\title{
COMPOSTO DE MARKETING EM EMPRESAS PROMOTORAS DE CONGRESSOS: ANÁLISE COMPARATIVA ENTRE CONCORRENTES E NÃO CONCORRENTE A PRÊMIO NACIONAL
}

Fábio Luciano Violin, Roberson da Rocha Buscioli, Renata Maria Ribeiro; Leonardo Giovane Moreira Gonçalves.

Universidade Estadual Paulista - UNESP, curso de Turismo, Rosana, SP. E-mail: violin@rosana.unesp.br

\section{RESUMO}

O presente estudo objetivou analisar os itens do composto de Marketing em empresas promotoras de congresso que concorreram a prêmio nacional em comparação com as que não concorreram com o intuito de observar semelhanças e diferenças relativas a temática. A amostra por conveniência estudou dois grupos com 15 integrantes cada um através da análise de seus planos de negócios configuraram o estudo como tendo natureza bibliográfica, exploratória e qualitativa. Os resultados indicam que existe diferença entre as que concorreram quando comparadas as que não concorreram apontando que o reconhecimento do mercado através da indicação ao prêmio não ocorreu por mero acaso pois, os dados indicam maior refinamento das que concorreram ao já mencionado prêmio.

Palavras-chave: Turismo, Marketing, Eventos, Composto de Marketing, Plano de Negócios.

\section{MARKETING MIX IN BUSINESS CONFERENCE PROMOTION: COMPARATIVE ANALYSIS OF COMPETITORS AND NOT COMPETITORS TO A NATIONAL AWARD}

\begin{abstract}
This study aimed to analyze the items of the Marketing Mix in companies promoting congress that competed for national award compared to those not competed in order to observe similarities and differences regarding the issue. A convenience sample studied two groups of 15 members each by analyzing their business plans have shaped the study as having literature, exploratory and qualitative nature. The results indicate that there is a difference between those who competed when compared to those who don't competes noting that market recognition through the award nomination don't occur by chance because the data indicate further refinement of that applied to the aforementioned award.

Keywords: Tourism, Marketing, Events, Marketing Mix, Business Plan.
\end{abstract}


INTRODUÇÃO

A concepção e os meandros que compõem a temática relativa a estratégia permeiam a algumas décadas tanto o discurso teórico quanto as ações de mercado nas mais variadas acepções e desdobramentos no tocante as relações entre as organizações e o ambiente em que se inserem. Para contextualização das análises posteriores primeiro se faz importante conceituar estratégia por considerar-se que os resultados obtidos em determinada organização em certo período de tempo decorre do conjunto de decisões ou ausência das mesmas postuladas e perseguidas através de um plano estratégico, nesse sentido Oliveira (1999, p.27) aponta que estratégia representa "[...] um caminho, ou maneira, ou ação estabelecida e adequada para alcançar os resultados da empresa, representados por seus objetivos, desafios e metas".

Após breve conceituação de estratégia se torna relevante salientar que esse processo estratégico se desencadeia graças ao ato de empreender o qual Drucker (1987) discorre como sendo o que é capaz de criar algo inovador com o poder de transformar "valores" através da constante busca por melhorias buscando constantemente a criação e fomento de oportunidades.

Partindo do pressuposto de análise desse estudo é preciso descrever o que vem a ser plano de negócios pois, o mesmo representa parte fundamental do processo de empreender pois, como afirma Dornelas (2001) planejar ações e definir o contexto de suas estratégias se mostra relevante nas mais diversas fases de uma empresa além de que as

"[...] mudanças de paradigmas deixam claro que as empresas e os seus profissionais sem planejamento, e que não possuam um alto grau de empreendedorismo dificilmente conseguem se manter competitivas, consequentemente ao longo do tempo acabam por fechar e desaparecer do mercado" (MICHEL, 2006, p.2).

Desse modo o plano de negócios pode representar ferramenta operacional capaz de auxiliar no delineamento das ações ideais na gestão organizacional com vistas a se atingir um ou mais objetivos. Porém, esse recurso não deve ser visto como a tabua de salvação ou elemento suficiente para assegurar sucesso se seguido.

Dentro do plano de negócios a parte em estudo diz respeito aos elementos do composto de Marketing e parte-se do pressuposto que tais elementos do composto desenvolvido por McCarthy (1996) na década de 1960 apresentam-se como relevantes na atualidade.

As estratégias mercadológicas vinculadas ao composto de promoção aqui associada ao processo de comunicação com o mercado e que foram alvo desse estudo são as mais recorrentes apresentadas pela literatura especializada especialmente as apontadas por Kotler (2009) e Las 
Casas (2007) a saber: I) Propaganda; II) publicidade; III) Vendas Pessoais; IV) Promoção de Vendas; V) Merchandising; VI) Relações Públicas; e por fim VII) Marketing Direto.

O próximo elemento do composto são as características do produto aqui entendidos como a oferta de um bem físico, serviço, ideia, lugar ou pessoa apresentando os benefícios que o comprador ou consumidor obtém a partir da troca. Quando o produto é definido nestes termos, desloca-se a ênfase do processo produtivo para o benefício a ser desfrutado (VIOLIN et al., 2013).

Dentre os elementos destacados pela literatura os mais recorrentes e que foram alvo desse estudo são apresentados por Kotler (2009): I) Marca; II) Embalagem e rotulagem; III) Serviços de apoio e assistência ao produto; IV) Qualidade; V) Estilo e design; VI) Garantias; VIII) Variedade de produtos e serviços; e VIII) Características da oferta.

O terceiro elemento foi inicialmente chamado no Brasil de Praça em referência ao termo original em inglês Place o qual sofreu transformações ao longo das décadas comportando a nomenclatura Logística dada sua abrangência e magnitude. Esse elemento está associado aos demais ao contemplar entre outras funções as determinações de onde, como, quando, de que forma e em quais condições um produto ou serviço deve ser disponibilizado a quem o consumirá.

As estratégias vinculadas ao composto de distribuição analisadas nesse estudo são: I) os Canais (caminho percorrido pelo produto na transferência de quem o produz até quem o consome podendo ser direto ou indireto) (KOTLER, 2009); II) a Cobertura (espaço geográfico coberto pela organização) (FERRELL et.al, 2000); III) a Variedade (conjunto de diferentes possibilidades pelos quais as ofertas podem ser combinadas) (CHURCHILL e PETER, 2005); IV) os Locais (ponto (s) de distribuição que a organização disponibiliza, bem como a natureza desses locais) (KOTLER, 2009); e V) Transporte (meios pelos quais os produtos serão deslocados) (LAS CASAS, 2007).

O composto de preço pode ser conceituado como o valor que o adquirente está disposto a dispensar na obtenção de algo, indo desde o escambo até a troca envolvendo dinheiro, em algumas circunstâncias o comprador pode acabar abrindo mão de elementos importantes não necessariamente financeiros como por exemplo, o tempo dispensado na busca por informações figuraria como uma espécie de custo para o consumidor (McCARTHY, 1996).

Kotler (2009) aponta as seguintes possibilidades de abordagens na determinação dos elementos do composto de preço: I) abordagem baseada no custo; II) abordagem baseada no valor; e III) abordagem baseada na concorrência. Cada abordagem faz referência ao seu ponto de contextualização estratégica. Nesse estudo emergiram informações relacionadas a um modo híbrido de abordagem vinculada ao elemento situacional, ou seja, a estratégia de determinação de preço pode variar conforme o ambiente em que a empresa opera. 
Os eventos promovidos por organizações públicas ou privadas podem configurar-se como poderosa ferramenta de comunicação estratégica com os mais diversos públicos - alvos desejados; além de um importante difusor da marca de uma empresa com poder para - se bem realizado promover produtos, serviços e ideias, além de potencializar vendas e contribuir para a expansão e a conquista de novos mercados (MIDDLETON e CLARKE, 2002; OLIVEIRA, 2005).

Dentre as possibilidades do segmento de eventos foram estudados os planos de negócios de empresas organizadoras de congressos internacionais, nacionais e regionais. Congresso pode ser conceituado como reunião de pessoas com interesse em área específica comum para discutir assuntos específicos de natureza científica ou relacionada a pesquisas.

O conceito de eventos ao qual esse estudo valida é o que apregoa que os mesmos são promoções humanas, direcionadas, com objetivo(s) delimitado(s) processado através de elementos vinculados ao planejamento, organização, direção e controle direcionado a público alvo específico com vistas a promoção específica de segmentos delineados e nominados.

O estudo que ora se apresenta teve como objetivo central o de levantar através da análise dos planos de negócios informações que permitissem a comparação entre organizações consideradas de certo modo referência ao serem indicadas a prêmio nacional com empresas similares do mesmo setor através dos elementos do composto de Marketing expressos em tais materiais.

\section{METODOLOGIA}

O primeiro elemento metodológico a ser destacado nesse estudo é a revisão bibliográfica realizada através de livros e artigos de natureza científica. Sua natureza descritiva se apresenta em função da pretensão inicial de estabelecer relação entre variáveis levantando dados relativos aos planos de negócio ou documentos similares providos pelas organizações participantes da amostra.

O estudo apresentou por sua natureza qualitativa a análise de trinta (30) organizações nacionais que promovem congressos sendo quinze (15) que concorreram a prêmio nacional da área de eventos no período de 2011 a 2014 e o mesmo número de organizações concorrentes similares que não concorreram a prêmio, e ainda cinco (5) de cada subgrupo (congresso internacional, nacional e regional).

Nesse contexto a escolha do público alvo foi seletiva considerando a dificuldade de acesso as mesmas bem como a determinação de um número mínimo de organizações de cada categoria e porte de atuação levaram esse estudo a apresentar a escolha da amostra por conveniência e a análise dos dados advindo de fontes documentais. Esse estudo não apresentou pesquisa com 
humanos mas, analisou tais documentos para apurar a frequência e nível de refinamento dos planos de negócio ou documentos equivalentes dessas organizações que levassem à inferência a respeito da relação entre os elementos do composto de Marketing já nominados e as organizações com o objetivo de responder a seguinte questão: as organizações que concorreram a prêmio nacional na área de eventos tem mais refinado seu composto de Marketing quando comparadas as que não concorreram a tal prêmio ou similares?

Os dados então se apresentam sob a forma de elementos estatísticos considerando sua frequência de aparição nos documentos analisados bem como seu nível de refinamento. Primeiro apresenta-se percentualmente a aparição de cada item no plano de negócios com sua respectiva porcentagem e após analisa-se através da escala de Likert com 5 pontos o grau de refinamento do item no plano sendo 1) Insuficiente; 2) Insatisfatório; 3) Mediano; 4) Satisfatório e 5) Excelente.

\section{RESULTADOS}

O primeiro conjunto de dados a ser apresentado diz respeito ao composto de Comunicação. Primeiro observou-se a frequência com que cada item do composto nominado no corpo teórico desse estudo figurava no plano de negócios das organizações de modo explícito ou implícito. Os dados apontam para os seguintes resultados:

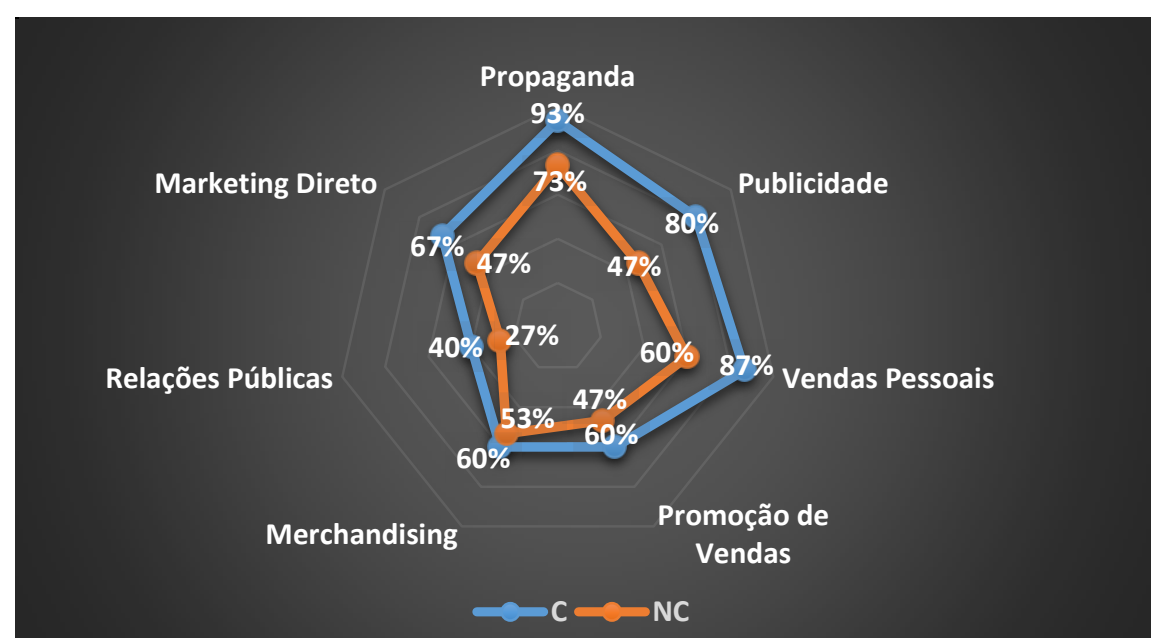

Figura 1. Frequência dos itens do Composto de Comunicação entre empresas Concorrentes (C) a prêmio nacional e Empresas não Concorrentes (NC)

Observa-se que a frequência com que cada item foi tratado pelas organizações concorrentes foi sobremaneira maior nas empresas que concorreram ao prêmio em detrimento das que não concorreram. De modo substancialmente equitativo o composto apresenta-se mais refinado nas empresas que concorreram ao prêmio, porém faz-se primordial acentuar que a exceção das Relações públicas todos os demais itens apresentaram indicadores em níveis 
satisfatórios positivos em ambas as categorias de organizações com grau de refinamento maior nas empresas concorrentes ao prêmio.

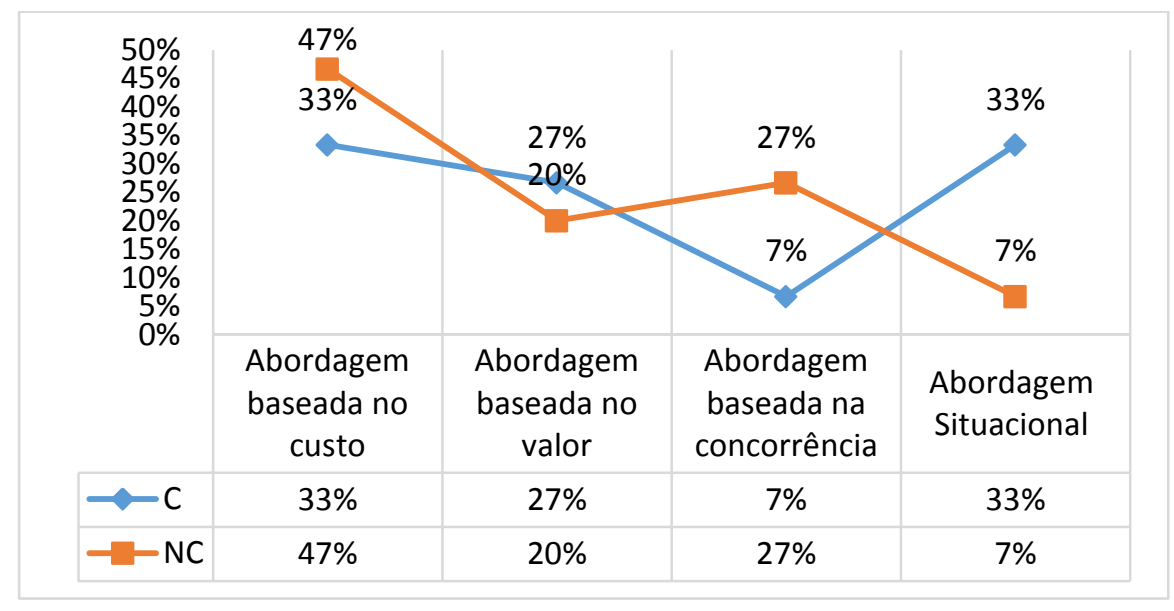

Figura 2. Abordagens estratégicas de preço entre empresas Concorrentes $(C)$ e não concorrentes (NC) a prêmio

A tabela indica a forma de atuação estratégica relacionada a preços praticadas pelas organizações. Observa-se a variação em termos de abordagens nas organizações com disparidade notória na alta aceitação de uma abordagem situacional, ou seja, baseada em um determinado momento do mercado nas empresas que concorreram ao prêmio em detrimento de baixa adesão a esse formato de competição. Observa-se também que a abordagem mais comum - baseada em custos - predomina em ambas as categorias de organizações. Faz-se indicativo de observação futura na abordagem de preço pautada na concorrência, amplamente adotada pelas empresas não concorrentes ao prêmio.

O composto de produto traz os seguintes dados:

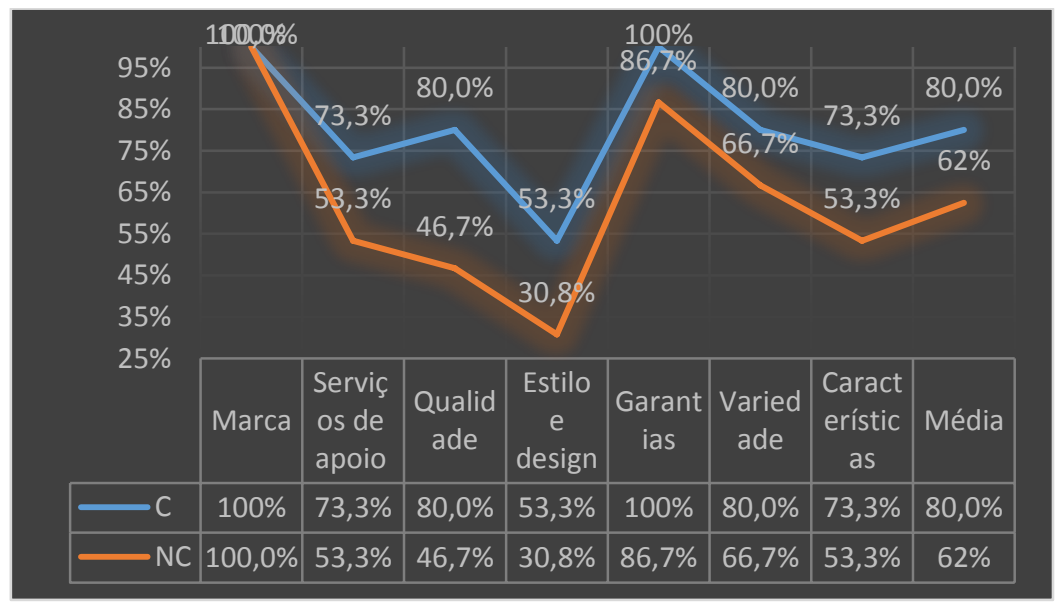

Figura 3. Frequência dos itens do Composto de Produto entre empresas Concorrentes (C) e Não Concorrentes (NC) a prêmio nacional. 
Aponta-se a diferença entre os tipos de organizações pautadas por suas médias finais de adesão e observação dos itens relacionados ao composto de Produto. A disparidade auxilia a observar o grau de relevância destinado a cada item. Em especial destaca-se a elevada preocução com a marca e as garantias. Os demais itens a exceção do estilo e design que não apresentaram-se destacados em maior monta a diferença entre as organizações fica evidente o que talvez auxilia a expandir as considerações considerando o destaque de uma sobre a outra.

O composto de Logística apresentou os seguintes dados:

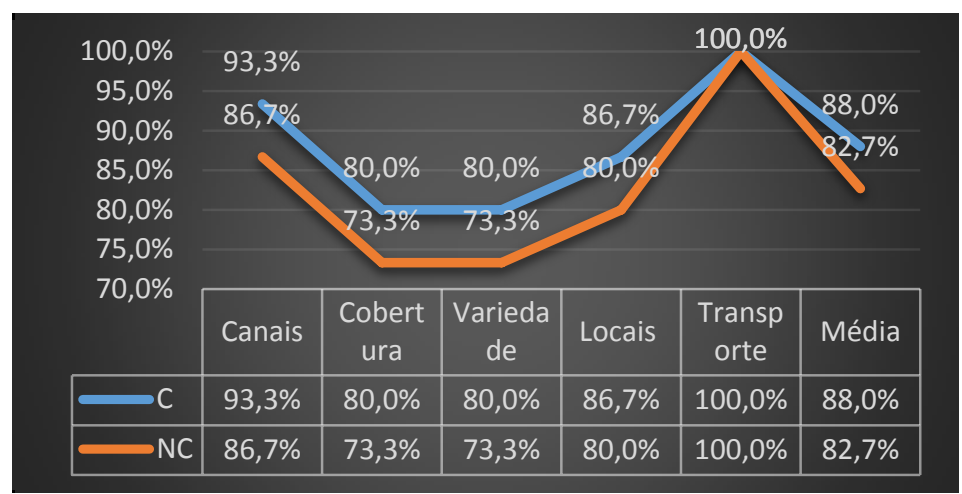

Figura 4. Frequência dos itens do Composto Logística entre empresas Concorrentes (C) e Não Concorrentes (NC) a prêmio nacional.

Esse último elemento apresentou as médias mais próximas entre empresas concorrentes e não concorrentes ao prêmio se comparado aos demais compostos. Observa-se que tradicionalmente os eventos apresentam elevado grau de complexidade no que diz respeito ao elementos logísticos e distribuição e nesse sentido pelo tradicional hábito de terceirização de processos meio e fim o composto apresenta o refinamento desse composto é o mais elevado na média.

\section{DISCUSSÃO}

No cômpito geral os elementos do composto apresentaram os seguintes dados: 


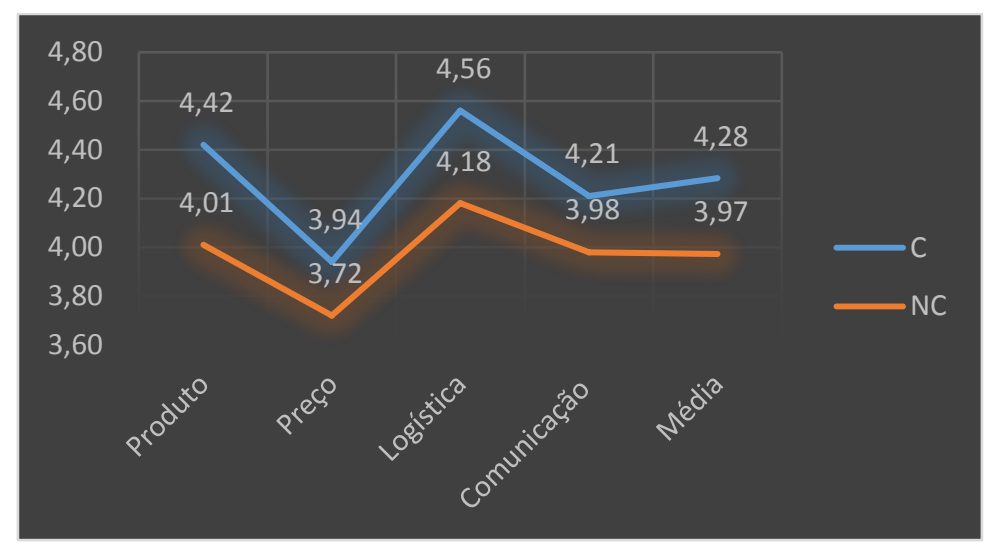

Figura 5. Composto de Marketing

Observa-se que o nível de refinamento do plano de negócio das empresas apresenta diferença positiva em favor das que concorreram a prêmio. Observa-se o refinamento de todos os itens a exceção do composto de preço que apresentou o menor nível de refinamento em suas propostas estratégicas. Através dos dados apresentados anteriormente apresentados é possível observar que em todos os casos as empresas de referência, ou seja, que concorreram a prêmio apresentaram indicadores superiores em relação as que não foram indicadas.

\section{CONCLUSÃO}

Aponta-se que as empresas que concorreram a prêmio apresentaram melhores indicadores do que as que não concorreram. A diferença entre elas na média é mais elevada nos compostos de comunicação e produto. O composto de logística apresentou maior grau de refinamento entre seus itens nas duas categorias de empresas aqui ressaltadas.

O composto de preço apresentou o menor refinamento entre todos os elementos além de apresentar diferenças substanciais de visão de mercado entre as organizações, destacando-se as abordagens distintivas especialmente no que diz respeito a abordagem baseada em custo e na baseada em concorrência que apresentaram valores inversos e mais gritante é a diferença na média da abordagem situacional.

Infere-se que as empresas concorrentes a prêmio na amostra pesquisada apresentam plano de negócios mais refinado se comparado a organizações que não concorreram.

\section{REFERÊNCIAS}

CHURCHILL, G. A. Jr., PETER, J. P. Marketing: criando valor para os clientes. São Paulo: Saraiva, 2005.

DORNELAS, J. C. A. Empreendedorismo: transformando ideias em negócios. 2o ed. Rio de Janeiro: Campus, 2005. 
DRUCKER, P. F. Inovação e espírito empreendedor: entrepreneurship. 2o ed. São Paulo. Pioneira. 1987.

FERRELL, O. C.; HARTLINE, Michael D.; LUCAS, George H. Jr.; LUCK, David. Estratégia de Marketing. São Paulo: Atlas, 2000.

KOTLER, P. Marketing para o século XXI: como criar, conquistar e dominar mercados. São Paulo: Ediouro, 2009.

LAS CASAS; A. L. Marketing de Serviços. 5 ed. São Paulo: Atlas, 2007.

McCARTHY, J. Basic Marketing a Global Managerial Approach. Richard Irwin, 1996.

MICHEL, M. Empreendedorismo: uma ferramenta para a prática da Administração e sua utilização em discentes dos de graduação em Administração. Revista Científica de Administração, São Paulo, v.6, n.1, p.1-8, 2006.

MIDDLETON, V. e CLARKE, J. Marketing de Turismo: Teoria e Prática. Rio de Janeiro: Campus, 2002.

OLIVEIRA, A. P. Turismo e Desenvolvimento: planejamento e organização. São Paulo: Atlas, 2005.

OLIVEIRA, D. de P. R. de. Excelência na Administração Estratégica: A competitividade para administrar o futuro das empresas. 4ำ ed. São Paulo: Atlas, 1999.

VIOLIN, F.L.; RIBEIRO, R. M.; BUSCIOLI, R.R da R; VIOLIN, A. L e VIOLIN, P. K. Terceirização no Setor de Eventos: Análise Contextual, Perspectivas e Formas de Uso. ADMPG: Congresso Internacional de Administração. s/d, 2013. 